\title{
Ameliorative Effects of Virgin Coconut Oil in Loperamide Induced Constipation in Wistar Rats
}

\author{
Adeniyi OS*, Edache M, Abi I, Ediale RJ \\ Department of Physiology, Faculty of Basic and Allied Medical \\ Sciences, Benue State University, PMB 102119, Makurdi, Nigeria \\ doi : https://doi.org/10.46912/jbrcp.149
}

\author{
*Correspondence: \\ Dr. Olasupo Stephen Adeniyi :supoadeniyi@yahoo.com
}

\begin{tabular}{|l|l|}
\hline $\begin{array}{l}\text { Article } \\
\text { information }\end{array}$ & $\begin{array}{l}\text { Date Submitted: 31/3/2020. } \\
\text { Date Accepted: 10/5/2020 } \\
\text { Date Published: June, 2020 }\end{array}$ \\
\hline
\end{tabular}

\begin{abstract}
Constipation is a common gastrointestinal disorder that affects people of all ages. Children and the elderly, are the most susceptible in whom treatment with orthodox drugs is often required. These drugs are however associated with many side effects, it is therefore important to develop drugs or natural products with less side effects. This research thus aims to investigate the effects of a natural product; virgin coconut oil (VCO) in the treatment of loperamide induced constipation in rats. Twenty-five male Wistar rats weighing 80-100 g were divided into 5 groups as follows: Group 1 was control group that received $5 \mathrm{~mL} / \mathrm{kg} /$ day normal saline (NS) only. All the other groups were treated with $4 \mathrm{mg} / \mathrm{Kg}$ loperamide to induce constipation. After 1 hour of loperamide treatment, animals in Group 2 were treated with $5 \mathrm{~mL} / \mathrm{kg}$ NS, Group 3 received $0.6 \mathrm{~mL} / \mathrm{kg} /$ day VCO (MVCO); Group 4, $0.9 \mathrm{~mL} / \mathrm{kg} /$ day VCO (HVCO) and Group $5 \mathrm{rats}, 2 \mathrm{mg} / \mathrm{kg}$ bisacodyl. The period of treatment was 3 days, and they were administered orally. Daily food consumption, number, weight and water content of feces, and intestinal transit time of charcoal meal were determined. Result showed that food consumption was significantly $(P<0.05)$ lower in loperamide alone group than other groups of animals. By days 1 and 3, the number of fecal pellets, weight of wet feces, weight of dry feces, and water content of feces in MVCO treated and control rats were significantly $(P<0.05)$ higher than loperamide $+N S$. The intestinal transit time in MVCO treated rats $(54.47 \pm 3.22 \%)$ was however not significantly different from loperamide $+N S(56.51 \pm 2.51 \%)$. In conclusion, VCO ameliorated loperamide induced constipation in the Wistar rats by increasing the frequency of defecation, weight and water content of feces.
\end{abstract}

Keywords: Constipation, Feces, Laxative, Virgin coconut oil

\section{INTRODUCTION}

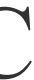
onstipation is a functional gastrointestinal disorder that affects all age groups worldwide. It is a condition of the gastrointestinal (GI) system, where a person has hard feces that is difficult to expel, infrequent stool and the sensation of incomplete evacuation of the fecal content of the gut. ${ }^{1,2}$ The incidence of constipation increases with age, and is more common in young and elderly females than in males. ${ }^{3,4}$ The causes of constipation include the use of organic compounds such as morphine, mental pressure, nutritional problems, secretory dysfunction, GI 
dysmotility and alterations in GI innervation., Constipation affects the quality of life as it can cause discomfort, abdominal distention, restlessness, vomiting and gut obstruction. ${ }^{7}$ Frequent constipation has also been recognized as a risk factor for colorectal cancer and some other functional GI disorders. ${ }^{8}$

Constipation is commonly treated by using laxatives, which can be classified into stimulant laxative and osmotic laxative. These drugs however have many side effects, which include abdominal blow up, vomiting and diarrhea. ${ }^{2,9}$ Therefore, it is necessary to develop herbal or natural products with less side effects.

Loperamide is an opioid agonist antidiarrheal drug that reduces the frequency of stooling. ${ }^{10}$ The drug inhibits intestinal water secretion and colonic peristalsis, which extends the fecal evacuation time and delays intestinal luminal transit. Thus, loperamide induces spastic constipation. ${ }^{?}$

Virgin coconut oil (VCO) is a functional food oil that is obtained from fresh, mature kernel of coconut by mechanical or natural means, with or without the use of heat and without chemical refining process (refined, bleached, deodorized). ${ }^{11,12}$ Virgin coconut oil is one of the emerging products that is attracting a lot of attention due to its medicinal and other valuable properties, which include: anti-microbial, anti-inflammatory, antihyperlipidemic and antioxidant properties. ${ }^{12}$ There are claims that VCO could cure constipation, but there is paucity of information about the scientific proof to back this up and the mechanism of action of the oil on constipation has not been elucidated. ${ }^{13}$

This study was therefore carried out to investigate the effects of VCO treatment on fecal (number, water content and weight) and peristalsis in loperamide induced constipation in rats. The laxative effects of VCO was compared with normal rats and bisacodyl (standard drug) treated rats.

\section{MATERIALS AND METHODS}

\section{Experimental Animals}

Male Wistar rats weighing $80-100 \mathrm{~g}$, purchased from the Animal House, College of Health Sciences, Benue State University, Makurdi were used. They were housed in the same facility, under an environmental temperature of $23 \pm$ $2^{\circ} \mathrm{C}$; humidity, $55 \pm 15 \%$ and $12 \mathrm{~h} \mathrm{light/dark} \mathrm{cycle.} \mathrm{Ethical}$ approval for the study was obtained from the Institutional Research and Ethics Committee of Benue State
University, Makurdi. The rats were kept in wire-meshed cages and fed with a standard pellet diet (Vital feeds, Grand Cereals LTD, Jos, Plateau State, Nigeria) with water ad libitum.

\section{Extraction of virgin coconut oil}

Hot extraction of virgin coconut oil (VCO) was done, because it has been shown that VCO obtained from hot extraction process contains more total polyphenol, antioxidant activity, tocopherol, phytosterol, monoglycerides, and diglyceride content than cold extraction.

Fully matured coconut nuts were selected, the shells were removed and the kernels were removed with a knife. The coconut kernels were then grounded using a mechanical grating machine. Coconut milk was extracted from the grated coconut meat using manually operated hydraulic coconut milk press. The coconut milk obtained from the first extraction was collected separately and the residue utilized for second and third extraction. The first, second, and third milk extracts were pooled by stirring vigorously for few minutes.

Coconut milk is an emulsion of oil and water. To recover the oil, coconut milk was heated in double-walled boiler known as VCO cooker under slow heating to coagulate the protein and release the oil. The oil was separated from the protenacious residue (kalkam) by straining the mixture through a muslin cloth. ${ }^{11}$

\section{Preliminary Study of effect of VCO on fecal Pellet Output}

The first experiment was done to determine the effects of $\mathrm{VCO}$ on fecal output in the animals with no other treatments. The doses of VCO used were in line with previous works. ${ }^{14}$ Twenty-five rats were fasted for 18 hours and divided into five groups of five rats each as shown below. Each animal was placed in separated cages. The cages were constructed such that the bottom was made up of wire gauze that have perforations enough just to permit the fecal pellets to fall down from the cage unto an underlying white paper:

Group 1: Control group which received $5 \mathrm{~mL} / \mathrm{kg} /$ day normal saline only

Group 2:Rats received low dose of virgin coconut oil $(0.3 \mathrm{~mL} / \mathrm{kg} /$ day $)$

Group 3: Rats were given medium dose of virgin coconut oil $(0.6 \mathrm{~mL} / \mathrm{kg} /$ day $)$

Group 4: Rats were given high dose of VCO 
$(0.9 \mathrm{~mL} / \mathrm{kg} / \mathrm{day})$

Group 5: Rats that received castor oil ( $1 \mathrm{~mL})$

After the treatments, fecal pellet output was counted hourly for four hours.

\section{Induction and Treatment of Constipation}

Twenty-five rats were randomly divided into five groups. Each of the groups excluding the control were administered $4 \mathrm{~mL} / \mathrm{kg}$ of loperamide an hour prior to treatment and these treatments were done for three consecutive days. ${ }^{2}$ Each rat was placed in separate cages. The daily weight and food consumption were monitored each day of the experiments. The doses of VCO used in these experiments were those that were more effective from Experiments 1; they were MVCO and HVCO.

\section{The groups are as follows:}

Group 1: Control group which received $5 \mathrm{~mL} / \mathrm{kg} /$ day normal saline.

Group 2: consisted of rats that received $4 \mathrm{mg} / \mathrm{Kg}$ loperamide $+5 \mathrm{~mL} / \mathrm{kg} /$ day

Group 3: Rats given $4 \mathrm{mg} / \mathrm{kg}$ loperamide + medium dose VCO (0.6mls/kg/day)

Group 4: Rats given $4 \mathrm{mg} / \mathrm{kg}$ loperamide + high

doseVCO $(0.9 \mathrm{mls} / \mathrm{kg} /$ day $)$

Group 5: Rats given that $4 \mathrm{~m} / \mathrm{kg}$ loperamide +bisacodyl $(2 \mathrm{~mL} / \mathrm{kg} /$ day $)$

Fecal pellets were observed and collected daily at

9.00am. They were counted, weighed immediately (wet weight), then dried for seven days and weighed again to obtain the dry weight.

\section{Determination of Water Content of faeces}

The water content of feces was determined as: $(g)=$ wet weight of feces $(\mathrm{g})$-dry weight of feces $(\mathrm{g})$

\section{Determination of weight of Food Consumed}

The weight of food consumed was calculated as:

Food consumed $(\mathrm{g})=$ Initial weight of feed(g)-final weight of feed $(g)$

\section{Determination of Intestinal Transit of Charcoal Meal}

Assessment of the gastrointestinal propulsion of a charcoal meal was determined following the method of Choi et al. $^{7}$ After the third day of experiments, the rats were fasted for $18 \mathrm{~h}$, but had free access to water. At the end of the period the animals were treated as described above (Induction and Treatment of Constipation). After 1 $\mathrm{h}$ of the treatments they were fed $1 \mathrm{ml}$ charcoal meal and at 30 min after the charcoal meal administration, the animals were sacrificed, the total intestine length (pyloric sphincter to cecum) and charcoal meal transit distance were measured. The intestinal charcoal transit ratio was calculated as follows:

Charcoal transit ratio $(\%)=[$ total distance traveled by charcoal meal/total small intestine length] $\times 100$.

\section{Statistical analysis}

Results were expressed as mean \pm SEM. Differences between the different groups were determined using Oneway ANOVA with LSD post hoc test. Data collected were analyzed using SPSS version 20.0 software (International Business Machines Corporation)

\section{RESULTS}

\section{Effect of VCO on fecal pellet output}

After 5 hours of treatment, results showed that the fecal pellet output in all the three VCO treated groups was significantly $(\mathrm{P}<0.05)$ higher than in control that was

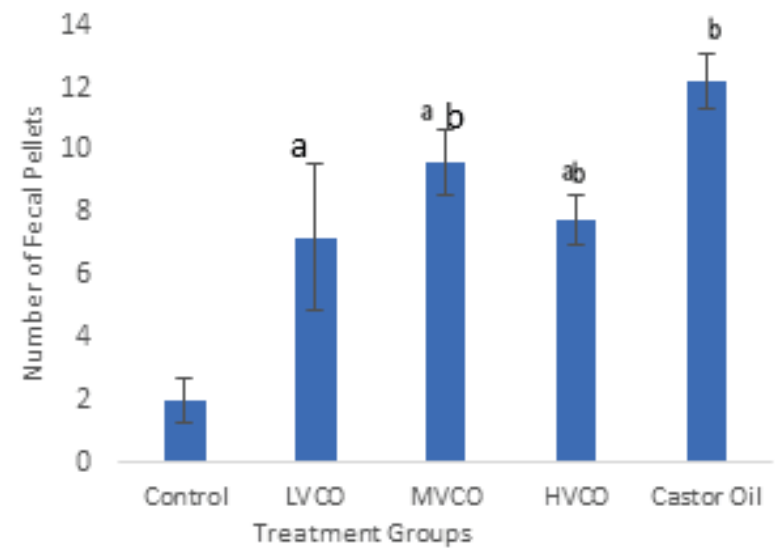

Figure 1: Effect of VCO on fecal pellet output

Values presented as mean \pm SEM. Groups with the same alphabets are not significantly different $(P>0.05) . L V C O=$ low dose VCO, $\mathrm{MVCO}=$ medium dose VCO, $\mathrm{HVCO}=$ high dose VCO 
given only normal saline, with medium dose VCO treatment having the highest fecal output. Furthermore, the fecal output in animals treated with castor oil was significantly $(\mathrm{P}<0.05)$ higher than in control, LVCO and HVCO as shown in Figure 1.

Effect of VCO Treatment on Food Consumption in Loperamide Induced Constipation

Result showed that by day 1 after treatments, food consumption in control, medium VCO, High VCO and bisacodyl treated were significantly $(\mathrm{P}<0.05)$ higher than in loperamide + normal saline (NS) treated rats. Food consumption reduced in all groups of animals by day 2 compared with the value by day 1 , except for loperamide + NS treated rats that showed an increase in food consumption by day 2 . By day 3 , the food consumption in

Table 1: Effect of VCO on Food consumption in loperamide induced constipation

\begin{tabular}{llll}
\hline Groups & Day 1 & Day 2 & Day 3 \\
\hline Control & $12.68 \pm 0.2 \mathrm{a}^{\mathrm{a}^{*}}$ & $11.56 \pm 0.84^{\mathrm{a}^{*}}$ & $12.98 \pm 1.50^{\mathrm{a}^{*}}$ \\
Loperamide + NS & $4.68 \pm 0.40^{*}$ & $6.40 \pm 2.09^{*}$ & $9.94 \pm 1.59^{\mathrm{b}}$ \\
MVCO & $9.88 \pm 0.42 \mathrm{ab}^{*}$ & $5.80 \pm 0.89$ & $11.94 \pm 0.23^{\mathrm{a}^{*}}$ \\
HVCO & $8.42 \pm 0.80 \mathrm{~b}^{*}$ & $8.22 \pm 1.60^{*}$ & $6.58 \pm 1.40$ \\
Bisacodyl & $12.22 \pm 2.03 \mathrm{a}^{*}$ & $6.06 \pm 1.97$ & $10.08 \pm 0.60^{\mathrm{ab}}$ \\
\hline
\end{tabular}

Data presented as Mean \pm SEM. Values with the same superscript across the rows or down the columns are not significantly different $(P>0.05)$. $L V C O=$ low dose VCO, MVCO = medium dose VCO, HVCO = high dose VCO, NS = Normal saline

control and MVCO were significantly higher $(\mathrm{P}<0.05)$ than in loperamide + NS treated rats. Furthermore, the food consumed by HVCO treated rats was significantly lower than the control and all treatment groups by day 3 (Table 1).

\section{Effect of VCO treatment on number of fecal pellets in loperamide induced constipation}

Result showed that the number of fecal pellets output were highest in control rats and this was significantly higher than all other groups on each of days 1 to 3 (Table 2). Furthermore, loperamide + NS treated rats had the least fecal pellet output and this was significantly $(\mathrm{P}<0.05)$ lower than all groups by days 1 and 3 . Medium and high doses of VCO significantly $(\mathrm{P}<0.05)$ increased the
Table 2: Effect of VCO on number of fecal pellet output in loperamide induced constipation

\begin{tabular}{llll}
\hline Groups & Day 1 & Day 2 & Day 3 \\
\hline Control & $50.80 \pm 0.66^{*}$ & $57.40 \pm 1.57^{*}$ & $65.20 \pm 1.59$ \\
Loperamide+ NS & $20.60 \pm 0.81$ & $31.80 \pm 2.46^{\mathrm{a}}$ & $29.20 \pm 2.63$ \\
MVCO & $38.20 \pm 1.83^{\mathrm{a}}$ & $36.20 \pm 2.71^{\mathrm{a}}$ & $37.00 \pm 1.76^{\mathrm{a}}$ \\
HVCO & $31.20 \pm 1.01$ & $35.80 \pm 2.29^{\mathrm{a}}$ & $37.80 \pm 4.07^{\mathrm{a}}$ \\
Bisacodyl & $40.20 \pm 2.60^{\mathrm{a}}$ & $34.60 \pm 2.66^{\mathrm{a}}$ & $48.20 \pm 4.29$ \\
\hline
\end{tabular}

Data presented as Mean \pm SEM. Values with the same superscript across the rows or down the columns are not significantly different $(P>0.05)$. $L V C O=$ low dose VCO, $M V C O=$ medium dose VCO, HVCO = high dose VCO, NS = Normal saline

number of fecal pellet output compared with loperamide + NS treatment. The number of fecal pellets in MVCO treated rats was not significantly $(\mathrm{P}>0.05)$ different from that caused by the standard drug bisacodyl on days 1 and 2 as shown in Table 2.

Effect of VCO Treatment of Weight on Wet Fecal Pellet Output in Loperamide Induced Constipation

By day 1 after treatments, the weight of wet feces excreted by the rats in control group was significantly higher than in all other treatment groups. Rat treated with loperamide $+\mathrm{NS}$ also had the lowest weight of wet fecal pellet output. The fecal weight in MVCO, HVCO and bisacodyl were not significantly different (Table 3). By day 2, weight of feces was significantly higher in control than all the treatment groups. The wet feces weight in HVCO was significantly $(\mathrm{P}<0.05)$ lower than in all other groups.

Table 3: Effect of VCO on weight of wet fecal pellet output in loperamide induced constipation

\begin{tabular}{llll}
\hline Groups & Day 1 & Day 2 & Day 3 \\
\hline Control & $11.06 \pm 0.39$ & $7.54 \pm 0.27$ & $7.58 \pm 0.61^{\mathrm{a}}$ \\
Loperamide + NS & $2.80 \pm 0.21^{*}$ & $5.92 \pm 0.53^{\mathrm{a}}$ & $3.56 \pm 0.48^{*}$ \\
MVCO & $5.16 \pm 0.05^{\mathrm{a}^{*}}$ & $6.20 \pm 0.41^{\mathrm{a}}$ & $5.36 \pm 0.66^{\mathrm{b}^{*}}$ \\
HVCO & $4.92 \pm 0.10^{\mathrm{a}}$ & $4.64 \pm 0.32$ & $4.82 \pm 0.54^{\mathrm{b}}$ \\
Bisacodyl & $5.64 \pm 0.37^{\mathrm{a}}$ & $5.46 \pm 0.21^{\mathrm{a}}$ & $6.76 \pm 0.95^{\mathrm{a}}$ \\
\hline
\end{tabular}

Data presented as Mean \pm SEM. Values with the same superscript across the rows or down the columns are not significantly different $(P>0.05)$ LVCO $=$ low dose VCO, $M V C O=$ medium dose $V C O, H V C O=$ high dose VCO, NS = Normal saline 
Furthermore, by day 3, the weight of wet fecal pellet output in loperamide + NS treated was significantly $(\mathrm{P}<$ $0.05)$ lower than all other groups. While the weight was not significantly different $(\mathrm{P}>0.05)$ in $\mathrm{MVCO}$ and $\mathrm{HVCO}$ as shown in Table 3.

\section{Effect of VCO treatment on Weight of Dry Fecal}

Pellets in Loperamide Induced Constipation

After 7 days of drying the collected feces, the weight of the dry feces was significantly $(\mathrm{P}<0.05)$ lower in loperamide $+\mathrm{NS}$ treated rats than in other groups except HVCO treated by day 1 of the experiments. By day 2, there was no significant difference $(\mathrm{P}>0.05)$ in the weights of dry feces

Table 4: Effect of VCO on weight of dry fecal pellet output in loperamide induced constipation

\begin{tabular}{llll}
\hline Groups & Day 1 & Day 2 & Day 3 \\
\hline Control & $6.70 \pm 0.37^{*}$ & $5.86 \pm 0.12^{*}$ & $5.68 \pm 0.56^{\mathrm{a}^{*}}$ \\
Loperamide + NS & $1.82 \pm 0.13^{\mathrm{a}^{*}}$ & $4.46 \pm 0.40^{\mathrm{a}}$ & $2.34 \pm 0.49^{*}$ \\
MVCO & $3.28 \pm 0.14^{\mathrm{b}^{*}}$ & $3.86 \pm 0.24^{\mathrm{ab}}$ & $3.90 \pm 0.68^{\mathrm{a}^{*}}$ \\
HVCO & $2.78 \pm 0.15^{\mathrm{ab}}$ & $2.92 \pm 0.12^{\mathrm{b}^{*}}$ & $4.06 \pm 0.54^{\mathrm{a}}$ \\
Bisacodyl & $3.22 \pm 0.30^{\mathrm{b}}$ & $4.44 \pm 0.25^{\mathrm{a}}$ & $5.48 \pm 0.93^{\mathrm{a}}$ \\
\hline
\end{tabular}

Data presented as Mean \pm SEM. Values with the same superscript across the rows or down the columns are not significantly different $(P>0.05)$. $L V C O=$ low dose VCO, $\mathrm{MVCO}=$ medium dose $\mathrm{VCO}, \mathrm{HVCO}=$ high dose $\mathrm{VCO}, \mathrm{NS}$ = Normal saline.

in loperamide + NS, MVCO, HVCO and bisacodyl treated rats. By day 3 however, the weight of dry feces in control, MVCO and bisacodyl treated rats were significantly $(\mathrm{P}<$ 0.05 ) higher than in loperamide $+\mathrm{NS}$ treated rats as shown in Table 4

Effect of VCO treatment on Water Content of Fecal Pellets in Loperamide Induced Constipation

Result showed the water content of the feces of control rats was significantly higher than other groups by day 1 . By the same day 1 , the water content of rats treated with

Table 5: Effect of VCO on Water content of feces in Loperamide Induced Constipation

\begin{tabular}{llll}
\hline Groups & Day 1 & Day 2 & Day 3 \\
\hline Control & $4.36 \pm 0.53$ & $1.94 \pm 0.10^{\mathrm{a}}$ & $1.90 \pm 0.08^{\mathrm{a}}$ \\
Loperamide + NS & $0.98 \pm 0.16^{*}$ & $1.40 \pm 0.12^{\mathrm{b}^{*}}$ & $1.22 \pm 0.06^{\mathrm{b}^{*}}$ \\
MVCO & $1.88 \pm 0.14^{\mathrm{a}^{*}}$ & $1.88 \pm 0.12^{\mathrm{a}^{*}}$ & $1.92 \pm 0.15^{\mathrm{a}^{*}}$ \\
HVCO & $2.14 \pm 0.14^{\mathrm{a}}$ & $1.72 \pm 0.22^{\mathrm{ab}}$ & $0.76 \pm 0.02^{\mathrm{b}}$ \\
Bisacodyl & $2.20 \pm 0.10^{\mathrm{a}^{*}}$ & $2.14 \pm 0.04^{\mathrm{a}^{*}}$ & $2.02 \pm 0.22^{\mathrm{a}^{*}}$ \\
\hline
\end{tabular}

Data presented as Mean \pm SEM. VValues with the same superscript across the rows or down the columns are not significantly different $(P>0.05) . \angle V C O=$ low dose VCO, MVCO = medium dose VCO, HVCO = high dose VCO, NS = Normal saline

MVCO, HVCO and bisacodyl was significantly higher than loperamide + NS treated rats. By days 2 and 3 respectively, the water content of control, MVCO treated and bisacodyl treated were significantly higher than loperamide + NS treated rats as shown in Table 5 .

Effect of VCO on body Weight Gain in Loperamide Induced Constipation

The body weight gain during the treatment period was

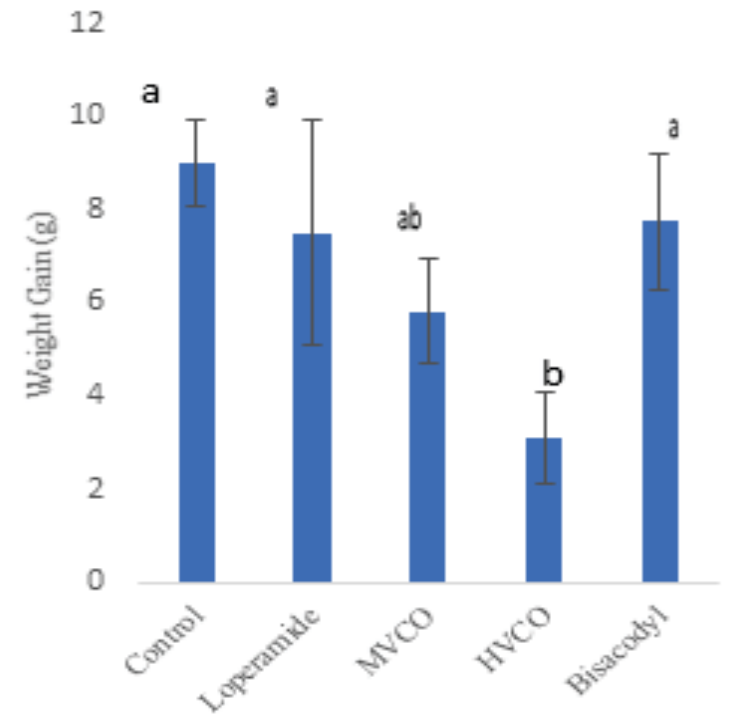

Figure 2: Effect of VCO on Weight Gain during Loperamide Induced Constipation

Data presented as Mean \pm SEM. Groups with the same alphabets are not significantly different $(P>0.05)$. $L V C O=$ low dose VCO, $M V C O=$ medium dose VCO, $H V C O=$ high dose VCO.

highest in control rats, but this weight gain was not significantly $(\mathrm{P}>0.05)$ different from loperamide $+\mathrm{NS}$, MVCO and bisacodyl treated rats. Rats that took HVCO had the least weight gain, which was significantly ( $\mathrm{P}<$ $0.05)$ lower than control and loperamide + NS treated rats (Figure 2).

Effect of VCO on Intestinal Transit

Result showed that intestinal movement of charcoal meal 
Table 6: Effect of VCO treatment on intestinal transit time

\begin{tabular}{llll}
\hline Groups & Total length & Distance traveled & Percentage distance traveled \\
\hline Control & $77.00 \pm 2.57^{\mathrm{a}}$ & $54.80 \pm 1.02^{\mathrm{a}}$ & $71.69 \pm 3.60^{\mathrm{a}}$ \\
Loperamide + NS & $85.20 \pm 1.17^{\mathrm{b}}$ & $48.10 \pm 2.05^{\mathrm{b}}$ & $56.51 \pm 2.51^{\mathrm{b}}$ \\
MVCO & $78.80 \pm 2.31^{\mathrm{a}}$ & $42.92 \pm 2.80^{\mathrm{b}}$ & $54.47 \pm 3.22^{\mathrm{b}}$ \\
HVCO & $77.60 \pm 2.50^{\mathrm{ab}}$ & $29.86 \pm 3.67$ & $39.07 \pm 5.45$ \\
Bisacodyl & $85.10 \pm 2.97$ & $56.00 \pm 2.86^{\mathrm{a}}$ & $65.63 \pm 1.26^{\mathrm{a}}$ \\
\hline
\end{tabular}

Data presented as Mean \pm SEM. Values in same column with the same alphabets in superscript are not significantly different $(P<$ 0.05). $L V C O=$ low dose VCO, MVCO = medium dose VCO, $H V C O=$ high dose $V C O, N S=$ Normal saline

was significantly $(\mathrm{P}<0.05)$ higher in control rats than loperamide + NS, MVCO and HVCO treated rats. The percentage distance travel of the charcoal meal was not significantly $(\mathrm{P}>0.05)$ different between loperamide + NS treated and MVCO treated. Intestinal transit was lowest in HVCO treated rats as shown in Table 6.

\section{DISCUSSION}

Constipation is a common gastrointestinal disorder characterized by poor movement and difficulty in defecation. The disease affects persons of different ages, but the incidence increases with age. ${ }^{2}$ Constipation causes discomfort, it greatly diminishes quality of life and brings about huge economic burdens on the patient. ${ }^{4}$

In researches, loperamide is often used as a constipation inducer. The drug is an opioid agonist that inhibits both intestinal water secretion and colonic peristalsis, these in turn extends fecal evacuation time and delays intestinal luminal transit. ${ }^{14,15}$ Therefore, the model of diarrhea induced by loperamide is considered to be spastic constipation. ${ }^{16}$ In this research, the observed reduction in the number, weight and water content of rats treated with loperamide and normal saline indicated that constipation was induced in the animals. This is in line with previous studies. ${ }^{7,16}$

The administration of VCO increased the frequency, weight and water content of fecal dropping in the rats. These are indications of the laxative properties of VCO. Thus, supporting the claim that VCO could be used in the treatment of constipation. The medium dose of VCO was however more effective than the high dose used in this study. Other herbal or natural products that are used in the treatment of constipation have same effect on the fecal characteristics. $^{4,7,16}$

The intestinal transit time of animals treated with medium dose VCO was not significantly different from animals treated with loperamide and normal saline within the time 1 hour after treatment. High dose VCO further slowed down intestinal motility. These show that the laxative effect of VCO does not include acceleration of intestinal movement. This is in line with the report of Mosińska et $a l$,which reported that VCO did not have any significant change in the rate of movement of the colon. ${ }^{17}$

The loperamide + normal saline treated rats ate the least quantity of food, yet, they had a higher increase in body weight during the period of study. The gain in body weight this group of rats had relative to the VCO treated groups may be due to the accumulation of fecal matter in their bodies, thus accounting for their extra weight. This indicates that VCO ameliorated the induced constipation. Furthermore, the loperamide + normal saline treated rats ate less food because their gut had contents that must be excreted in order for them to eat. The effect of VCO on weight gain is similar to the reports of Niwa et al. and Wintola et al. ${ }^{18,19}$

Many orthodox drugs such as osmotic or secretory laxatives and bulking agents are used worldwide in the treatment of constipation. Many of these drugs however impose high financial burden and some of them have side effects. ${ }^{4}$ As a result, it is worthwhile to search for medicinal plants with laxative effects, cost effective with minimal side effects and many medicinal plants have been used locally for the treatment of constipation. Virgin coconut oil is a natural product that can be consumed as meal and at the same time has been found to be useful in the treatment of various ailments. Thus, VCO could be used for the treatment of constipation with minimum side effects.

\section{CONCLUSION}

In conclusion, this present study revealed that oral administration of virgin coconut oil exhibited laxative effect in loperamide induced constipation. This it does by increasing the water content of the feces; this in turn increases the frequency of defecation and the quantity (weight) of feces. The laxative effect of VCO is however more effective at $0.6 \mathrm{~mL} /$ day in Wistar rats. These findings have provided scientific support to the claim that VCO ameliorates constipation. More work however needs to be 
done to further elucidate the laxative mechanisms of VCO.

\section{Conflict of Interest}

None declared

\section{REFERENCES}

1. Eor JY, Tan PL, Lim SM, Choi DH, Yoon SM, Yang SY, et al. Laxative effect of probiotic chocolate on loperamide-induced constipation in rats. Food Res Int. 2019; 116:1173-1182. doi:10.1016/j.foodres.2018.09.062.

2. Lee S-G and Kang H. Ameliorative effect of Houttuynia cordataThunb (Saururaceae) leaf extract in loperamideinduced constipation in rats. Trop J Pharm Res. 2019; 18(8): 1727-1732.

3. Ali MZ, Mehmood MH, Saleem M, Gilani A-H. The use of Euphorbia hirta L. (Euphorbiaceae) in diarrhea and constipation involves calcium antagonism and cholinergic mechanisms. BMC Complement Med Ther 2020; 20, 14. https://doi.org/10.1186/s12906-019-2793-0.

4. Yan S, Yue Y, Wang X, Dong H, Wu B, Qian H. Aqueous Extracts of HerbaCistanche Promoted Intestinal Motility in Loperamide-Induced Constipation Rats by Ameliorating the Interstitial Cells of Cajal. EVID-BASED COMPL ALT 2017. ID 6236904, 13 pages. https://doi.org/10.1155/2017/6236904.

5. McQuade RM, Stojanovska V, Abalo R, Bornstein JC, Nurgali $\mathrm{K}$. Chemotherapy-induced constipation and diarrhea: pathophysiology, current and emerging treatments. FRONT PHARMACOL 2016; 7, 414. doi: 10.3389/fphar.2016.00414.

6. Gallagher PF, O'Mahony D, Quigley EM. Management of chronic constipation in the elderly. Drugs Aging 2008; $25: 807-821$

7. Choi J-S, Kim JW, Cho H-R, Kim K-Y, Lee J-K, Sohn JH, et al. Laxative effects of fermented rice extract in rats with loperamide-induced constipation. Exp Ther Med. 2014; 8(6): 1847-1854. doi: 10.3892/etm.2014.2030.

8. Simons CC, Schouten LJ, Weijenberg MP, Goldbohm RA, van den Brandt PA. Bowel movement and constipation frequencies and the risk of colorectal cancer among men in the Netherlands cohort study on diet and cancer. Am J Epidemiol 2010; 172(12):1404-1414. doi: 10.1093/aje/kwq307

9. Portalatin M and Winstead N. Medical management of constipation. Clin Colon Rect Surg 2012; 25(1):12-19. doi:
$10.1055 / \mathrm{s}-0032-1301754$

10. Kojima R, Doihara H, Nozawa K, Kawabata-Shoda E, Yokoyama T, Ito H. Characterization of two models of druginduced constipation in mice and evaluation of mustard oil in these models. Pharmacol 2009; 84:227-233. doi: 10.1159/000236524.

11. Srivastava Y, Semwal AD, Majumdar A, Yildiz A. (2016). Quantitative and qualitative analysis of bioactive components present in virgin coconut oil. Cogent Food Agric 2016; 2: 1164929. http://dx.doi.org/10.1080/23311932.2016.1164929

12. Rohman A, Irnawati, Erwanto Y, Lukitaningsih E, Rafi M, Fadzilah NA, et al. (2019). Virgin Coconut Oil: Extraction, Physicochemical Properties, Biological Activities and Its Authentication Analysis Food Rev Int 2019 DOI: 10.1080/87559129.2019.1687515

13. El-Meidany WMR, Tayel DI, Waly MI. Can Virgin Coconut Oil be the Neutraceutical for Chronic Constipation among Autistic Children: A Case Study. Canad J Clin Nutr 2019; 7 (1):26-33.

14. Okafor JO, Joshua PE and Ukegbu CY. Anti-ulcer and hematological properties of virgin coconut oil (VCO) against indomethacin-induced gastric ulcer in experimental rats. Afr. J. Pharm. Pharmacol 2018; 12(24): 46-355

15. Hughes S, Higgs NB, Turnberg LA. Loperamide has antisecretory activity in the human jejunum in vivo. Gut 1984; 25: 931-5.

16. Aikawa N, Ohmori K. Effect of Zaldaride Maleate, and antidiarrheal compound, on fecal pellet output induced by hyperpropulsion in gastrointestine of rats. Jpn J Pharmacol $2000 ; 82: 350-2$.

17. Nweje APC, Idakwoji PA, Iserhienrhien LO, Sheneni VD, Momoh TB. Laxative Effects of Aqueous Extract of SidaacutaLeaves in Loperamide- Induced Constipation in Wistar Rats.AJRIMPS 2019; 6(1): 1-7.

18. Mosińska P, Szczepaniak A, WojciechowiczT, Skrzyski M, Nowak K, Fichna J. Chain length of dietary fatty acids determines gastrointestinal motility and visceromotor function in mice in a fatty acid binding protein 4-dependent manner. Eur J Nutr. 2019. https://doi.org/10.1007/s00394019-02094-2. [Epub ahead of print]

19. Niwa T, Nakao M, Hoshi S, Yamada K, Inagaki K, Nishida M, et al. Effect of Dietary Fiber on Morphine-induced constipation in Rats. Biosci Biotechnol Biochem 2002; 66(6): 1233-1240. doi:10.1271/bbb.66.1233.

20. Wintola OA, Sunmonu TO, Afolayan AJ. The effect of Aloe ferox Mill. in the treatment of loperamide-induced constipation in Wistar rats. BMC Gastroenterol 2010; 10,95. doi:10.1186/1471-230X-10-95. 